\title{
Standard Versus Low Dose Steroid Therapy in the First Attack of Childhood Nephrotic Syndrome
}

\author{
Niru Prabha Saharia,Vivekananda M.S \\ (Department Of Paediatrics, Guwahati Medical College, Assam)
}

The Nephrotic syndrome is one of the commonest renal diseases in children .The word "Nephrosis"or what is often called primary nephritic syndrome had its origin in the early part of $20^{\text {th }}$ century and was described as a clinical condition of edema and proteinuria where the Kidney demonstrated (light microscopy) degeneration of tubule associated with renal glomeruli.

The problem of Nephrotic syndrome continues to pose a major challenge in paediatric nephrology. Although the disease may affect 2 children per 1,00,000 annually ,most patients suffer from a chronic course that last several years. There is considerable associated morbidity and a significant proportion of patient may eventually develop end stage renal disease. Even in the mildest from of nephrotic syndrome i.e the child withMCNS is manifested by an intial attack

1. May require hospitalization,

2. A prolonged period of initial treatment ( i.e a minimum of 8 weeks)

3. Require frequent monitoring both at home and by physician visits,

4. Require a treatment program with a drug having known and significant adverse effects

5. Has a high rate of recurrence i.e relapse in $>60 \%$ cases

6. Where relapse are having associated with common illness acquired every day activities i.e day care,school,and gatheringand additionally where the progression of chronic renal failure is always there.

In these patients who do demonstrate multiple relapse ,the potential for problem continue to be high and include longterm immunosuppression,serious infection during such period and also thereafter. Exposure to cytotoxic drugs decreases linear growth,behavioural effect from steroid obesity,cataract,hypertension,osteoporosis,osteomalacia,nephrolithiasis, diabetes mellitus, hirsutism, gingival hypertrophy and others.

The management of nephrotic syndrome require patience and understanding and co- operation of the family besides the medical expertise. Prednisolone is the referred drug till today though exact mode of action is still unknown. It used as a palliative therapy and different schedule were adapted by different paediatricnephrologist based on their personal experience. The first schedule was employed by international study of kidney disease in 1960 which was modified subsequently by diff nephrologist.

Attempt has been made worldwide to use different regime of steroid keeping in mind the relapse rate and toxic effect of steroid.A full proved standard regime is yet to be achieved,However study by Barry L Warshow and Leonard C Hymens(Emory university school of Medicine ,AtlantaMay1989) and Hiraoku M.tsukahara Horulu et.al (Sept 2000) showed that reduced dose steroid was equally effective in including remission with less side effect of steroid.With this backdrop the present study was carried out during the period of 2001 to 2002 in the Dept of Paediatrics,GMCH.

\section{Objective}

The study was conducted during the period 2001-2002 in GMCH in the Dept of Pediatric Objective of the study was ,to observe the responsiveness and rate of relapse with low dose $(1 \mathrm{mg} / \mathrm{kg})$ versus standard dose $(2 \mathrm{mg} / \mathrm{kg})$ of steroid in first attack also to evaluate the risk factors for predicting the relapse.

Design: Prospective study

\section{Material And Mathod}

After clearance from ethical committee,total sixty(60) cases of nephrotic syndrome of first attack in the age group of 1 to 15 years was selected.

All were admitted for therapeutic trial steroid therapy with standard and low dose $1 \mathrm{mg} / \mathrm{kg}$ was given at random. Out of 60 cases, 32 cases were treated with $2 \mathrm{mg} / \mathrm{kg}$ and 28 cases treated with $1 \mathrm{mg} / \mathrm{kg}$. Treatment protocol was follows as First episode of nephrotic syndrome 


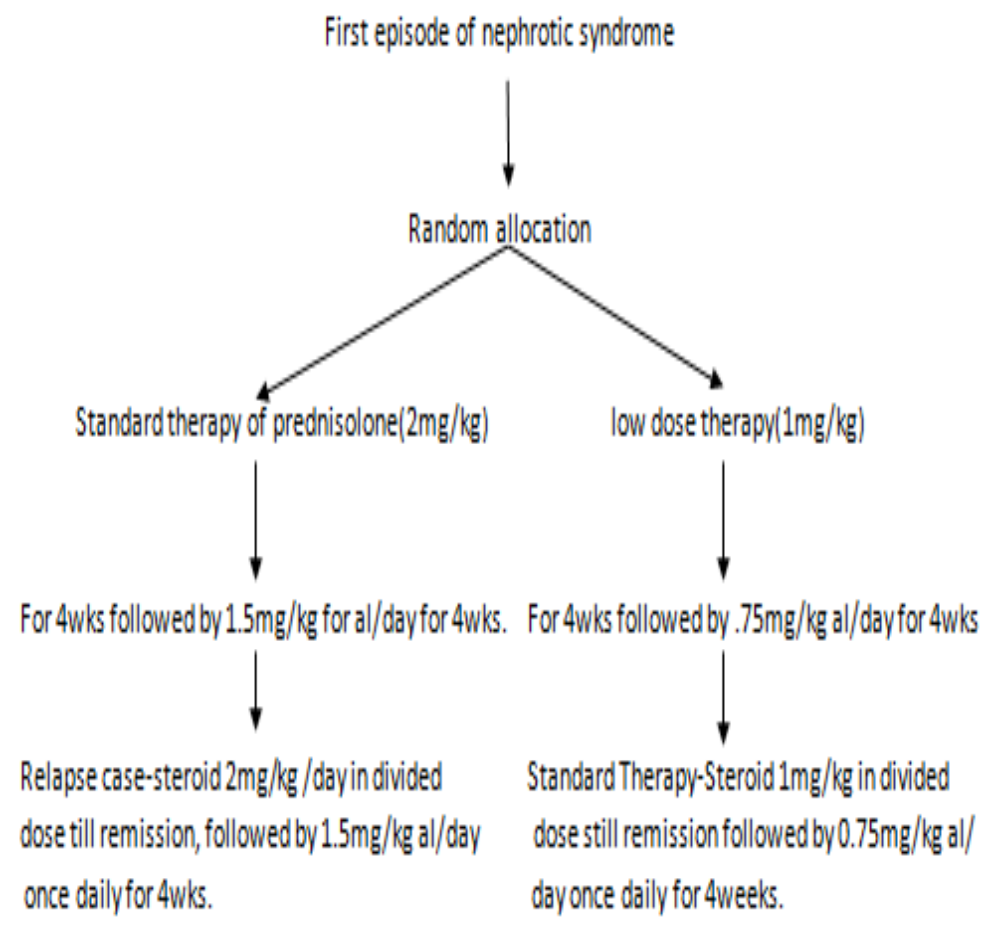

For evaluation of risks factors during the first yea,two groups were combined together. All cases were discharged after achieving remissions.Follow-up were done in the renal clinic periodically every 15 days interval in for 2 months.After that every month interval for one year to 18 months.During follow-up,body weight, blood pressure, urine for proteinuria by heat coagulation test and other toxicity was recorded. A definite scheme of case taking was followed in each case using a proforma.

Stastical analysis was done using $\mathrm{t}$-test and chi-square test.Significance was determined by $\mathrm{p}$ value It was considerd significant when $\mathrm{p}<0.01$

\section{Result}

Out of sixty cases 30 cases were given low dose of steroid $(1 \mathrm{mg} / \mathrm{kg})$ for the initial attack and 28 cases was given convention dose of steroid $(2 \mathrm{mg} / \mathrm{kg})$ and followed up for at least one year. It has been seen that time of response in the control group was 3-14days $(7.8+2.5)$ and in trial group it was 2-8days(5.3=1.9)that is shorter which is statistically significant $(\mathrm{p}<0.05)$. But the interval between stoppage of steroid and onset of relapse in control group was 7-270(76.3=82.9) and in trial group itwas 7-365days $(124.3=131.5)$ which is statistically not significant(p.>0.05). The pattern of relapse in control group was such single attack (37\%),infrequent relapse(18.5\%), $\mathrm{FR}+\mathrm{SD}(48.4 \%)$, and in trial group it was single attack $(57.2 \%), \operatorname{IR}(10.18 \%)$, and $\mathrm{FR}+\mathrm{SD}(33.8 \%)$ There are no significant diefference $\mathrm{p}>0.05$

The incidence of steroid toxicities in the control group was 55.6\% and in trial group itwas $44.4 \%$ which is statistically significant where $\mathrm{p}$ value $\mathrm{P}<0.05$.

We also analysed the co relation of different risk factors in relation of relapse.It was observed that there was no relation between age,sex, presence of hypertension, hematuria with different pattern of relapse. Where there was no significant correlation between those. These finding was similar to the observation in the study of international kidney diseses in children (1978),Siegel NJ Goldleny B (1972) and LERAUND R (2000). It may be the histological finding rather than the age and other associated finding which predict the prognosis.

Comparison of time of response*:

\begin{tabular}{|l|l|l|l|l|}
\hline STUDY GROUP & NO. OF CASES & $\begin{array}{l}\text { RANGE IN } \\
\text { DAYS }\end{array}$ & MEAN \pm SD & $\begin{array}{l}\text { STANDARD } \\
\text { ERROR }\end{array}$ \\
\hline $\begin{array}{l}\text { STANDARD } \\
\text { DOSE }\end{array}$ & 32 & $3-14$ & $7.8 \pm 2.5$ & 0.45 \\
\hline LOW DOSE & 28 & $2-8$ & $5.3 \pm 1.9$ & 0.37 \\
\hline
\end{tabular}

Time of response*: From first day of initiation of therapy to first day of protein free urine for three consecutive days. 


\section{Discussion}

In 1967 ,the international study of Kidney diseases in children,arbitrarily chose a regimen for treating the intial attack of Idiopathic Nephrotic syndrome,consisting of prednisolone administrated daily for 4 weeks followed by 4 weeks of intermittent therapy.Till now many pediatric nephrology used different regimens though the intial dose of steroid was according to the ISKDC.In the present study clinical trial was done with low dose steroid i.e $1 \mathrm{mg} / \mathrm{kg}$ as an intial dose. Daily individed doses for 4 weeks,followed by $0.75 \mathrm{mg} / \mathrm{kg}$ on alternate days for 4 weeks in the initial attack of nephrotic syndrome. The steroid responsiveness and further clinical course were compared with the standard dose of steroid inthe age group of 1.5-14 years $(4.8+2.7)$ with a male female ratio 2.9:1. All were followed up periodically in renal clinic for a period of 6-12 months. Four cases from group and seven cases from the trial group were excluded due to lowcompliance.Total twenty one(21)cases in trial group and twenty eight cases from control group were compared after one year of follow up.

The time of response between the two group were as follow in the trial group it was ranged from 2-8days $(5.3 \pm 1.9)$ andincontrol group it ranged from 3-14 days $(7.8 \pm 2.5)$ with a $P$ value $<0.05$ which was statistically significant. This finding can be compared by the study done by Baryl Warshaw, Emory University ,school of Medicine,Atlanta where it was found to be effective in inducing remission with a low dose of steroid (0.2$1.5 \mathrm{mg} / \mathrm{kg}$ ) in intial attack and also in relapse cases.Here the time of response was ranged 2-10days (6days) which was similar to the present study.

The time interval between the stoppage of steroid and the date of relapse was ranged 7-270days (76.3 \pm 82.9$)$ in control group and 7-365 days $(124.3 \pm 131.5)$ in trial group with a $P$ value.$>0.05$ which was statistically not significant. After twelve months of follow up,the status of patients in the two groups were compared, in trial group rate of relapse after 6 months and after 12 months were $61.9 \%$ and $81 \%$.In control group the rate of relapse after 6 and 12 months were $77.8 \%$ and $85.2 \%$. respectively.It was observed that control group had a higher rate of relapse than the trial group.Comparison was done by chi-square test resulting a $\mathrm{P}$ value $>0.05$ which was non-significant.

The different pattern of relapse of the two groups were compared In trial group,the incidence of single attack was $12(57.2 \%)$,infrequent relapse $4(10.1 \%)$ and frequent relapse 5 and dependent (33.8\%).In control group single attack 10(37\%),infrequent relapse 5(18.\%)and steroid dependent $12(48.4 \%)$. It was observed that there was higher incidence of single attack i.e $57.2 \%$ in trial group as compared to control group i,e $48.4 \%$ than trial group33.8\%.But there was no statistically significant difference in pattern of relapse of the two $\operatorname{group}(\mathrm{p}>0.05)$

In the present study,probable risk factors or variables for relapse were evaluated. One of the difficult problems in the childhood nephrotic syndrome is the occurrence of relapse despite of intial response to steroid.Though the ultimate response is quite good for most of the patients, effort could be directed towards minimising the complication of steroid and cytotoxic drugs, In the present study,the dependent variables were age,sex, time of response, presence of hematuria and hypertension and independent variable was pattern of relapse. It was observed that there was no relation between age, sex presence of hematuria with pattern of relapse. These finding were similar to the observation in the study done by the international study of kidney diseases in children (1978),Siegel NJ Goldberg B,Krassn(1972) and Alexander R. Contantinesco (2000). So it may be the histopathological finding rather than the age at onset that predicted a worse prognosis.

\section{Conclusion}

Treatment with low dose of steroid observed to be equally effective in inducing remission when compare to standard dose. However sign of steroidtoxicities were less in trial group.It also observed that there were no relation between age, sex, presence of hypertension, hematuria with the relapse rate.

To get a clear picture more studies with large number of cases preferably in multi-centric concentrating mainly on comparison of low dose versus standard dose. This will go along way in management of chronic disease with high rate of relapse and risk of morbidity during the prolonged course of treatment.

\section{BIbliograpy}

[1]. Pediatr1979 :95:23999-243:international study of Kidney disease in children: Nephrotic syndrome in children:a randomised trial comparing two prednisone regimes in steroid responsive patient who relapse early.

[2]. Siegel NJ,Golfberg B, Krasher LS and Haystelt:long term follow up in children with steroid responsive nephrotic syndrome :J Pediatr81:257:1972

[3]. Hiraoka M,Takeda N, Tsukahara H et.al,favourable course of steroid responsive nephrotic children with mild initial attack,Kidney Int1995:47:1392-1393/

[4]. Habib R,KleenlnechtC,The primary nephrotic syndrome in children;classification and clinicopathological study of 406 cases:Pathil Annual17971c $: 417=474$. 